\title{
A equidade aristotélica e a correção da lei
}

\author{
Matheus Teixeira da Silva ${ }^{1}$
}

Resumo: O texto volta-se ao estudo da noção de epieikeia (equidade) na tradição aristotélica, procedendo-se à análise do instituto e a uma tentativa crítica de conceituação, destacando-se o problema da generalidade da lei e da singularidade dos casos. Ainda, vê-se brevemente a epieikeia na obra de Tomás de Aquino.

Palavras-chave: Equidade; epieikeia; Aristóteles; praeter legem; contra legem

\section{Aristotelian equity and correction of law}

Abstract: The text aims to study of the notion of epieikeia (equity) in the Aristotelian tradition, proceeding the analysis of the institute and a critical attempt of conceptualization, highlighting the problem of the generality of the law and the singularity of the cases. Still, the Epieikeia is briefly seen in the work of Thomas Aquinas.

Keywords: Equity; epieikeia; Aristotle; praeter legem; contra legem

\section{INTRODUÇÃO}

O conceito aristotélico de justiça é bastante conhecido e desperta atenção de muitos investigadores; das ideias aristotélicas, entretanto, preocupamo-nos com uma breve investigação a respeito do que seja a equidade (epieikeia), a qual possui um papel de relevo para o filósofo (DAL MASS, 2000, p. 115), sendo seu aparecimento considerado inédito a partir dos textos de Aristóteles, como apontam diversos estudiosos da matéria, ainda que algum dissenso possa existir a respeito. ${ }^{2}$

\footnotetext{
${ }^{1}$ Advogado, graduado em Direito pela PUCRS. Pós-graduado em Direito do Estado pela UFRGS. Pós- graduado em Direito Processual Civil pela PUCRS. Pós-graduado em Direito Empresarial pela PUCRS. Mestre em Filosofia pela PUCRS. Doutorando em Ciências Jurídicas pela Universidade Autónoma de Lisboa. Email: matheus@matheusteixeira.com

2 "The earliest account of the nature of equity and equitable judgment is found in the writings of Aristotle." (SHINER, 1994, p. 1245-1264.); "A noção de equidade (epieikeia) tem origem aristotélica (...).” (DAVID, 2015, p. 10-34.); "Foi todavia Aristóteles quem primeiramente fixou (...) os contornos do problema. A ele remonta a definição da equidade como a Justiça do caso concreto.” (ASCENSÃO, 1984, p. 496/497.); TEIXEIRA, 2012, p.
} 
O significado de epieikeia, ordinariamente, pode ser associado à ideia de excelência, ou mesmo bondade, no sentido amplo de uma virtude, como refere Portalis: "Le mot équité est susceptible de diverses acceptions. Quelquefois il ne désigne que la volonté constante d'être juste, et dans ce sens il n’exprime qu'une vertu.” (PORTALIS, 2004, p. 88.)

Aqui, porém, referimo-nos a uma noção mais específica de epieikeia, utilizada por Aristóteles, correspondente a um tipo particular de excelência, associado à capacidade de correção da lei; tal virtude específica desempenha, com efeito, uma função social específica de retificação da lei, como reconhece Shiner:

Aristotle pithily caracterizes epieikeia in the specific sense as an epanorthoma nomou, hei elleipei dia to kathoulou, 'a correction of law, where law falls short because of its universality.' The Rhetoric describes the equitable as to para to gegrammenon nomon dikaion, 'that justice which lies beyond the written law'. (SHINER, 1994, p. 12451264.)

Deste modo, a partir de análise bibliográfica de diversos matizes, o presente estudo tem por objetivo um exame a respeito da natureza da equidade aristotélica, almejando à demonstração de sua capacidade operativa enquanto instrumento capaz de promover a correção da lei na aplicação do caso concreto, no sentido originariamente descrito por Aristóteles.

\section{Equidade como correção da lei}

Para toda lei elaborada presume-se a existência de uma relação lógico-intencional entre seu antecedente (suporte fático; hipótese normativa; protasis) e seu consequente (prescrição; cominação; apodosis) $^{3}$, no intuito de que, uma vez havido o antecedente, o consequente promova um fim legítimo e esperado pelo tecido social, ou seja, algo útil ao bem comum e harmônico à concepção de justiça adotada pela comunidade. Atienza e Manero

\footnotetext{
88-92. Em sentido diverso, Alejandro Alvarez reconhece que Aristóteles é responsável por estabelecer os alicerces e a sistematização da discussão, atribuindo a Platão o papel de "preparar o terreno". (ALVAREZ, 2012, p. 23-25.) Colhe-se da obra de Platão o exemplo de alguém que recebesse armas de um amigo e este, posteriormente, tomado pela loucura, pedisse-as de volta. Platão reconhece que o justo seria a não-devolução, de modo que o exemplo se afeiçoa à ideia de epieikeia, dada a exceção que surge pela peculiaridade do caso. (PLATÃO, 2014, p. 9, 331c.) António Menezes Cordeiro também discorda: "Cabe ainda recordar que a epieikeia não é de invenção aristotélica. Ela surgia já em Heródoto. Mas com um sentido diferente.” (CORDEIRO, 2016, p. 596.)

${ }^{3}$ Oliveira Ascensão afirma ser de difícil aceitação o termo 'hipótese normativa', refutando também Tatbestand e fattispecie, aceitando apenas o termo latino facti species. (ASCENSÃO, 1984, p. 423.)
} 
A equidade aristotélica e a correção da lei

explicam a estrutura da regra, segundo os quais “(...) sua estrutura consiste em um antecedente ou condição de aplicação, que contém um conjunto fechado de propriedades; e um consequente ou solução normativa (...).” (ATIENZA; MANERO, 2014, p. 19.)

Há casos, porém, nos quais uma vez verificado o antecedente, o consequente não atende à sua pressuposta finalidade (MACDONALD, 2010, p. 99). Em casos tais, que fogem à ordinariedade, deve-se pensar em alguma solução para evitar a disfuncionalidade do sistema jurídico-normativo. A equidade aristotélica, com efeito, desempenha um papel de relevo justamente neste contexto (ALVAREZ, 2012, p. 28), já que pretende solucionar esta dissintonia.

Como sintetiza Tiago David, o que ocorre é que “algo formalmente subsumível ao suporte fático da norma não enseja a aplicação da respectiva consequência jurídica” (DAVID, 2015, p. 10-34), porque em tais casos excepcionais esta é a única forma de não se chancelar iniquidades quando da aplicação da regra, ainda que formalmente subsumível (SILVA, 2015, p. 40.)

O pensamento peripatético, ao assentar a concepção de epieikeia, perpassa pela relevante noção da importância que deve ser atribuída às circunstâncias e particularidades dos casos concretos que se examinem (HOBUSS, 2010, p. 163-174). Nesse sentido, fundamental a análise da Ethica Nicomachea, porquanto seu Livro V apresenta a compreensão de Aristóteles sobre o assunto, que assim consigna:

A origem da dificuldade é que a equidade, embora justa, não é a justiça legal, porém retificação desta. A razão para isso é que a lei é sempre geral; entretanto, há casos que não são abrangidos pelo texto geral da lei ou por esta ou aquela regra legal geral. Em matérias, portanto, nas quais embora seja necessário discursar em termos gerais, não é possível fazê-lo corretamente, a lei toma em consideração a maioria dos casos (...). E isso não faz dela uma lei errada, pois o erro não se encontra na lei e nem no legislador, mas na natureza do caso, uma vez que o estofo das questões práticas é essencialmente irregular. Quando, portanto, a lei estabelece uma regra geral e, posteriormente, surge um caso que apresenta uma exceção à regra, será, então, correto (onde a expressão do legislador - em função de ser ela absoluta - é lacunar e errônea) retificar o defeito (preencher a lacuna) decidindo como o próprio legislador teria ele mesmo decidido se estivesse presente na ocasião em particular e teria promulgado se tivesse sido conhecedor do caso em questão. (ARISTÓTELES, 2002, p. 160) 
Como se verifica do trecho transcrito, Aristóteles sustenta que a equidade (epieikeia) é o mecanismo com o qual se pode proceder à correção da lei: isto ocorre porque a generalidade inerente à lei inviabiliza que esta possa regular a totalidade de casos possíveis (CHROUST, 1942, p. 119-128). Não se cuida, portanto, de suposta falha quanto ao conteúdo normativo da própria regra, mas de uma efetiva "impossibilidade de haver uma legislação minimamente detalhista” (CAMPELO, 2010, p. 29) para todos os casos possíveis.

Como explica Eduardo Bittar, "não se trata de um erro legislativo, mas, sim, de um problema oriundo da própria peculiar conformação das coisas como são praticamente”, em consonância à nossa interpretação”. (BITTAR, 2005, p. 165.) ${ }^{4}$ A razão de tal problema é também explicitada por Ascensão, segundo o qual “a lei, por natureza genérica, não pode descer à infinita diversificação dos casos da vida.” (ASCENSÃO, 1984, p. 501.)

Assim, justamente porque a lei é necessariamente genérica por natureza é que Aristóteles reconhece, em sua obra Política, a inexorável precariedade, da lei:

Tal como nas demais artes, também é impossível codificar exatamente tudo o que se aplica à organização da cidade: as regras escritas são necessariamente genéricas mas as acções referem-se a casos particulares.” (ARISTÓTELES, 1998, p. 149, 1269a.)

Deste modo, a lei, enquanto previsão hipotética (hipótese normativa), limita-se aos casos mais comuns, ou seja, à ordinariedade, àquilo que se pode razoavelmente prever quando do âmbito da formulação das hipóteses normativas - “les lois ne sont donc instituées qu’en gros et pour la plupart des cas (hôs epi to polu)” (MICHON, 2010, p. 33-48.) - correspondendo à ideia do exercício de uma função legislativa típica.

Nesse sentido, Gadamer explica que “Aristóteles mostra que toda lei é geral e não pode conter em si a realidade prática em toda a sua concreção, na medida em que se encontra numa tensão necessária com relação ao concreto da ação.” (GADAMER, 2014, p. 419.) Gadamer ${ }^{5}$ igualmente aponta nesse sentido da imperfeição da norma, ponderando que "a lei é sempre deficiente, não em si mesma, mas porque, frente ao ordenamento a que se destinam as

\footnotetext{
${ }^{4}$ Bittar, entretanto, sustenta em duas obras uma hipótese distinta, mais ampla, mencionando "erros legislativos e demais hipóteses de produção de injustiça decorrente da generalidade do preceito legal aplicado à realidade fática (...)”. (BITTAR, 1997, p. 69; BITTAR, E 2003, p. 1056.)

5 “'Gadamer foi um dos responsáveis pelo resgate da filosofia prática de Aristóteles no Século XX. Segundo ele, é impossível interpretar a regra de forma separada de sua aplicação; isso estaria no modelo Aristotélico: a união entre os três níveis hermenêuticos indissociáveis: compreensão, interpretação e aplicação.” (ALVAREZ, 2012, p. 44.)
} 
leis, a realidade humana é sempre deficiente e não permite uma aplicação simples das mesmas” (GADAMER, 2014, p. 419).

Há, inequivocamente, abstração e universalidade nos preceitos normativos, e é por esta razão que os vícios aparecem, sem que se possa imputar ao legislador um erro na formulação do comando geral: "The mistake, Aristotle says, is really in neither the law nor the legislator, but 'in the nature of the business', - euthus gar toiaute he ton prakton hule estin." (SHINER, 1994, p. 1245-1264.)

Em outras palavras, significa dizer que a epieikeia, “dirigida contra uma subsunção mecânica” (HÖFFE, 2008, p. 205), é um corretivo do justo legal, estando legitimada pelo reconhecimento da inexorável imprecisão da lei, defeito este decorrente da impossibilidade prática de legislar-se sobre todos os casos com nível de detalhamento suficiente: o legislador legisla para os casos cotidianos, presumíveis, previsíveis.

Ainda, pode-se atribuir à epieikeia uma “função atualizadora da lei”, no sentido indicado por Tiago David, a fim de evitar um anacronismo da lei:

\footnotetext{
Esta dimensão da equidade é menos conhecida e não aparece expressamente desenvolvida por Aristóteles, mas é plenamente compatível com a noção. Afinal, a atenção às singularidades do caso concreto, ao invés de subsunção acrítica e automática em face do comando geral do legislador, revela-se plenamente compatível com o reconhecimento da inaplicabilidade da norma quando esta tem o propósito de regular situação diversa, não mais existente. (...) é bastante razoável que dada a alteração das circunstâncias que ensejaram a edição da lei, esta não mais seja aplicada ante a mudança do contexto que se teve em vista quando editada a legislação. Uma lei em absoluto descompasso com a realidade não se presta a manifestar o modo pelo qual a comunidade deseja ver resolvida a questão (...). (DAVID, 2015, p. 10-34.)
}

O objetivo do instituto da epieikeia, ou melhor, da virtude da equidade (MACDONALD, 2010, p. 100), é bastante claro: fazer com que a regra previamente posta pelas instâncias legitimadas de modo geral possa ser adaptada/corrigida às particularidades do caso, isto é, “(...) to fit the circumstances of a particular case (...)” (CHROUST, 1942, p. 119-128.). Höffe entende esta correção do que é ditado pela lei como um “melhoramento” (HÖFFE, 2008, p. 204). 
A consequência, pois, é a atribuição de poder ao aplicador da lei, o qual deverá agir como se legislador fosse ${ }^{6}$ quando tornar-se impossível a subsunção do particular ao universal (CHROUST, 1942, p. 119-128). A equidade, assim, é alçada à condição de um instrumento utilizável pelo julgador para adaptar a norma ao caso, no intuito de que "da observância de uma estrita legalidade não se venha a ser mais arbitrário do que onde as leis não estão presentes.” (BITTAR, 2005, p. 167)

Na Política, Aristóteles afirma a necessidade de se conceder supremacia aos magistrados tão-somente quando se verificar um caso no qual a lei não pudesse ter feito adequada previsão anterior, decorrente da já mencionada "dificuldade de promulgar leis que prevejam todos os casos” (ARISTÓTELES, 1998, p. 231, 1282b).

A criatividade do aplicador da lei, todavia, é mitigada ${ }^{7}$, já que este não deve aplicar ao caso o seu próprio entendimento sobre o que seja o melhor, mas deve, ao contrário, agir pensando em como o legislador teria prescrito a norma legal ao caso em exame se as particularidades do caso tivessem sido objeto de atenção quando da elaboração da regra geral, como destaca Chroust: “(...) deciding as the lawgiver would himself decide if he were presente on the occasion, and would have legislated if he had been cognizant of the case in question." (CHROUST, 1942, p. 119-128.) Há evidente espaço, porém, à crítica para um possível e nefasto subjetivismo - risco inerente à tarefa de julgar. ${ }^{8}$

Para Aristóteles, “não é propriamente o homem que governa, mas a lei” (HÖFFE, 2006, p. 247 ), motivo pelo qual a solução do caso deve passar, senão pelo que o legislador disse, pelo que diria.

Nas palavras de Hobuss:

Deste modo, quando uma lei não prevê os casos particulares que podem ocorrer em dadas circunstâncias, em função da não previsão dos mesmos pelo legislador, é necessário que haja uma correção da lei, levando em consideração, é importante

\footnotetext{
6 "Dans un cas, le juge envisage ce que le législateur aurait porté dans la loi s’il avait prévu le cas particulier qui lui a échappé, la lacune est involontaire, et le juge se glisse alors dans la peau du législateur, non pour légiférer (il n’a pas ce droit), mais pour faire comme s’il devait légiférer." (MICHON, 2010, p. 33-48.); "O sujeito, aqui, subroga-se na própria posição do legislador”. (BITTAR, 2005, p. 165); CAMPELO, 2010, p. 29; SHINER, 1994, p. 1245-1264; ZIPPELIUS, 2012, p. 250.

${ }^{7}$ Em sentido contrário, Morrall menciona "uma ampla gama de poderes discricionários”. (MORRALL, 2000, p. 60.)

8 "Les ennemis de l'équité diraient que l'arbitraire sentimental de la conscience du juge trouverait ici une porte d'entrée.” (MICHON, 2010, p. 33-48.); “Às vozes favoráveis à primazia da justiça de caso concreto face à justiça de caso-regra opõem-se outras, que receiam que uma justiça de caso concreto conduza à arbitrariedade e à insegurança jurídica.” (ZIPPELIUS, 2012, p. 251.)
} 
ressaltar, o que o próprio legislador teria dito quando confrontado a este caso particular, ou o que teria prescrito na lei se tivesse conhecido o que está em questão. (HOBUSS, 2010, p. 163-174)

A esse respeito, Aristóteles é explícito ao tratar do equitativo em sua Retórica, assim dispondo: "Ser equitativo é mostrar indulgência ante as fraquezas humanas; é também levar em conta menos a lei do que o legislador; considerar não a letra da lei, mas a intenção do legislador"; ato contínuo, acrescenta o filósofo a importância de considerar "não tanto este ou aquele detalhe parcial, mas o todo” (ARISTÓTELES, 2013, p. 108, 1374b1), mostrando consonância à ideia que associamos à noção de “coerência”.

Percebe-se, com clareza, que no pensamento aristotélico as apreensões do sentido da regra, bem como sua aplicação, não guardam limites estreitos. O filósofo parece nutrir um certo receio em relação à adequação/justeza da justiça legal, como se depreende de seus comentários: "Preferimos dirimir um desentendimento por meio da negociação do que mediante recurso à justiça; preferimos uma arbitragem a um litígio, já que o árbitro leva em conta a equidade, ao passo que o juiz leva em conta a lei.” (ARISTÓTELES, 2013, p. 108, 1374b1). Isto porque Aristóteles reconhece a imperfeição da lei posta e o risco de sua aplicação conduzir a uma iniquidade.

O que caracteriza, portanto, a ideia de epieikeia é o reconhecimento de que qualquer regra genérica pode possuir uma exceção ${ }^{9}$ e o não reconhecimento desta circunstância pode ocasionar uma injustiça quando da aplicação da lei, genérica por natureza. Perelman, nesse sentido, explica que se apela ao "senso de equidade [do juiz] quando a lei, aplicada rigorosamente (...), ou quando o precedente, seguido à letra, conduzem a consequências iníquas.” (PERELMAN, 1996, p. 163.)

Assim explica Höffe:

\begin{abstract}
Uma aplicação literal das leis existentes pode, sem dúvida, segundo Aristóteles, conduzir ocasionalmente a uma flagrante injustiça, motivo pelo qual ele considera como necessário corretivo uma justiça para o caso individual, a equidade (epieikeia: Ética a Nicômaco, V, 14). (HÖFFE, 2006, p. 247.)
\end{abstract}

\footnotetext{
9 “This exception to the general rule of the strict Common Law constitutes the Aristotelian 'Equity' wich is but a 'rectification of the strict Common Law, particularly wherever the latter proves itself defective because of its generality”'. (CHROUST, 1942, p. 119-128.)
} 
Pertinente notar que Aristóteles não prega a desnecessidade da lei ao recorrer à equidade $^{10}$, uma vez que a norma geral se preocupa com a ideia de igualdade (HÖFFE, 2008, p. 206), o que é necessário. A propósito, Aristóteles vislumbra no governo das leis uma superioridade, na medida em que estas são livres de paixões, ao contrário dos homens - muito embora estes tenham melhores condições de tomar decisões para os casos particulares, o que viabiliza o uso da equidade:

A lei é isenta de paixão ao passo que qualquer alma humana forçosamente a possui. Mas sem dúvida dir-se-á que, em compensação, um homem decide melhor em casos individuais. Vê-se que este homem deve ser necessariamente um legislador e que existir leis; mas estas não devem ter a supremacia quando se desviam da sua finalidade (evidentemente que devem ser supremas nos outros casos). (ARISTÓTELES, 1998, p. 251, 1286a.)

Nesse sentido, o equitativo não é o justo segundo a $l e i^{11}$, embora seja justo; é justo, porém, por ser a correção da lei (DAL MASS, 2000, p. 115), “abrandando o rigor ou sobrepassando as disparidades e iniquidades engendradas pelas leis obsoletas e descontextualizadas.” (BITTAR, 1997, p. 69). E este direito corrigido, produto da epieikeia, é melhor do que a prescrição legal, como apontado por Gadamer: "Atenuando a lei não faz reduções à justiça, mas encontra um direito melhor. Em sua análise da epieikeia, a equidade, Aristóteles formula isso com a mais precisa das expressões: epieikeia é a correção da lei.” (GADAMER, 2014, p. 419.)

Disso surge uma importante observação a ser feita: ao se adotar a compreensão aristotélica da epieikeia se faz uso de um elemento que está fora da lei para julgamento do caso posto à apreciação.

\footnotetext{
10 "Ainda que advertindo a respeito da impossibilidade da aplicação de uma norma abstratamente considerada, obviamente Aristóteles não defendeu o caos, o casuísmo e a anomia. Aristóteles defendia a existência de regras prévias, mas condicionava a aplicação a uma situação de normalidade (...).” (DAVID, 2015, p. 10-34.) A respeito, também Alvarez: ALVAREZ, 2012, p. 46.

11 “Não é verdade que o équo seja o justo segundo a lei (ou tò katà nómon dé), de acordo com o que está consignado no corpo legislativo e foi posto pela vontade humana como vinculativo da conduta social, mas sim um corretivo do justo legal (epanothoma nomímou díkaion).” (BITTAR, 2005, p. 164.)
} 


\section{A equidade aristotélica e a correção da lei}

Há, neste ponto, uma divergência entre os intérpretes de Aristóteles: para alguns ${ }^{12}$ dentre os quais Goytisolo, Portalis ${ }^{13}$ e Bittar (BITTAR, 1997, p. 69) -, a epieikeia conduziria à busca pelo direito natural para corrigir a insuficiência do justo legal:

Podríamos calificar de ordenamiento abierto el integrado, en Grecia, por cosmos, nomos y taxis; y, en el campo del derecho, el inmerso en el de la justicia, ya sea natural, to dikaion phisikon, bien positiva, to dikaion nomikon, que tanto dimana la ley positiva como dela convención. Entre los mundos de ambas justicias, que eran comunicables, pues cada uno estaba abierto al otro, penetraba la epiqueya que, basada en lo justo natural, excluía la aplicación de lo justo positivo. (GOYTISOLO, 1991, p. 279)

Em contrapartida, e em nosso entender com razão, alguns autores, dentre os quais Shiner (SHINER, 1994, p. 1245-1264) e Michon ${ }^{14}$ - além de MacDonald, em dissertação (MACDONALD, 2010, p. 102), - sustentam que o texto aristotélico não legitima esta interpretação.

Isto porque a própria ideia da epieikeia conduz o julgador à posição de alguém que deve agir como se legislador fosse, ou seja, deve pensar em como a lei deveria ter sido prescrita àquele caso, o que, salvo melhor juízo, não está necessariamente associado à busca do direito natural. Ao contrário, busca-se tão somente uma “correção” do justo legal para que este seja compatível ao caso concreto: não para refutar o justo legal em sua generalidade, portanto, mas para preservá-lo - com as devidas adaptações para o caso concreto (SHINER, 1994, p. 12451264).

Em síntese, no contexto do pensamento aristotélico o gênero do justo é constituído por duas espécies, quais sejam, o justo legal e a equidade: ambos possuem a mesma finalidade (promoção da justiça) e atuam de modo complementar, na medida em que, quando houver falha na lei, caberá ao julgador (ou mesmo ao cidadão) ${ }^{15}$ agir como teria agido o legislador caso pudesse prescrever para aquele caso concreto (DAL MASS, 2000, p. 167).

\footnotetext{
12 Para um panorama mais abrangente, a tese de Alvarez: ALVAREZ, 2012, p. 40.

13 "L’équité est le retour à la loi naturelle, dans le silence, l'opposition ou l'obscurité des lois positives." (PORTALIS, 2004, p. 22.) Michon critica Portalis diretamente: "Mais contrairement à ce que dira Portalis, Aristote affirme que l'équitable est un correctif (epanorthoma) du juste légal, et le fondement de la correction ne renvoie pas à une loi naturelle, mais tout simplement à l'intention du législateur, à l'esprit contre la lettre de la loi." (MICHON, 2010, p. 33-48.)

14 “La doctrine aristotélicienne originale voit dans l'epieikeia non pas un complément mais une correction de la loi positive, et elle n’est pas fondée sur une quelconque référence à la loi naturelle.” (MICHON, 2010, p. 33-48.) 15 “Além dessa forma judicial de aplicação da equidade, outra há comum a todo homem, cultivável como qualquer virtude e disposição do caráter.” (BITTAR, 2005, p. 167.)
} 
Há, nesse sentido, uma rica complexidade no pensamento aristotélico, ao formular noções de sabedoria prática (aplicáveis à ética e ao direito) para contextos de modelação da universalidade formal da lei para a singularidade concreta e particular do caso:

Eis a razão pela qual a filosofia ética e política de Aristóteles pode, num certo sentido, contribuir para reabilitar aquela clássica noção de prudência ou sabedoria prática (phronesis) cujo exercício se traduz na modelação da universalidade formal de uma norma ou lei na singularidade material de uma situação concreta e particular em contextos decisionários de elevada densidade crítica, como a ética, a política e o direito, entre outros mais. (AMARAL, 2014, p. 17.)

Deste modo, deve ser reconhecida a impossibilidade de encerramento da esfera da deliberação política no plano universal e abstrato da lei, por mais detalhista que esta pretenda ser. ${ }^{16}$

No período da Modernidade, cumpre notar, o combate à tarefa interpretativa dos dispositivos legais (visando à certeza e à segurança) conduziu a um forte declínio do uso da noção de epieikeia aristotélica ${ }^{17}$, porquanto redutora da previsibilidade, transformando-se a equidade em um elemento totalmente distinto daquele que se fazia presente no contexto do estagirita $^{18}$, mostrando-se importante tal cautela terminológica a fim de não se atribuir à equidade aristotélica o conteúdo da “equidade contemporânea”, ou o contrário.

A compreensão que se firmou hodiernamente a respeito do que seja equidade (inclusive no direito brasileiro) ${ }^{19}$ relaciona-se a uma ideia de "bom-senso", a um poder discricionário explicitamente conferido ao julgador para às hipóteses de inexistência absoluta de norma para o caso $^{20}$ - o que, com a devida vênia, não parece plausível em razão da força

\footnotetext{
16 “(...) la prudence est la vertu de la raison dans son activité de délibération sur l’action à entreprendre. Elle ne peut se contenter d'appliquer des règles générales, car elle doit considérer des circonstances toujours particulières." (MICHON, 2010, p. 33-48.); MacDONALD, 2010, p. 105.

17 "O fato, porém, é que a lição de Aristóteles foi esquecida: a equidade foi tragada pelo direito moderno, avesso a qualquer possibilidade de subjetivismo na aplicação da lei pelo juiz.” (GRAU, 2008, p. 282.)

18 "Sendo a aplicação da premissa maior ao caso por mera conformação literal, tal como um encaixe gramáticoconceitual, restava vazia a epieikeia aristotélica e inviabilizando o exercício da prudência, sendo tanto melhor juiz aquele mais subserviente.” (DAVID, 2015, p. 10-34.)

${ }^{19}$ Veja-se o texto do Código Tributário Nacional: "Art. 108. Na ausência de disposição expressa, a autoridade competente para aplicar a legislação tributária utilizará sucessivamente, na ordem indicada: I - a analogia; II - os princípios gerais de direito tributário; III - os princípios gerais de direito público; IV - a equidade.”

20 "A solução pela equidade é a solução de harmonia com circunstâncias do caso concreto, e não com quaisquer injunções, mesmo indiretas, do sistema normativo.” (ASCENSÃO, 1984, p. 355.); "Tal uso não encontra correspondente na tradição aristotélica, ainda que guarde uma certa relação com a função individualizadora. Na falta de uma especificação da solução a ser adotada, adota-se aquela aconselhada pelo bom senso, mas desta vez
} 
normativa dos princípios, sempre presentes, ainda que com concretude rarefeita. Não se trata, pois, da equidade aristotélica.

Ademais, cabe uma brevíssima ponderação sobre a correção da lei fundada na epieikeia: seria a decisão fundada na epieikeia uma decisão contra legem ou praeter legem? Alguns (DAVID, 2015, p. 10-34) defendem de forma plausível e compreensível que não se trata de uma decisão contra legem porquanto se preserva o espírito da norma, a qual não havia sido feita para aquele caso particular, o que configuraria decisão praeter legem; há, todavia, aqueles (MICHON, 2010, p. 33-48) que vislumbram na decisão fundada na epiekeia uma decisão contra legem propriamente dita. Isto porque, uma vez reconhecido que o antecedente normativo (suporte fático) esteja configurado, agir-se-ia de forma contra legem acaso se decidisse pela não-aplicação do consequente normativo.

Não se trata de valorar negativamente a decisão ao denominá-la de contra legem, mas tão somente de classificá-la de contra legem porque não aplica a consequência legal mesmo reconhecendo que está preenchido o suporte fático da norma. Embora Aristóteles não o diga expressamente, depreende-se ser essa sua compreensão, já que classifica o equitativo como o justo, embora não o justo segundo a lei (CARMIGNANI, 2009, p. 116); ou seja, é um justo contra legem. No mesmo sentido aponta Tomás de Aquino, como adiante será demonstrado. Pode-se compreender, entretanto, que se cuide de uma decisão praeter legem, por preservar o espírito da norma.

\section{Equidade em Tomás de Aquino}

O sentido da aequitas é fortemente marcado pelo pensamento grego (CORDEIRO, 2016, p. 594). A propósito, para Tomás de Aquino, a aequitas relaciona-se ao problema da generalidade das leis, servindo como mecanismo para aferição das exceções decorrentes: “A epieikeia está, em Aquino, intimamente ligada à ideia de exceção - inclusive esvaziando bastante os outros significados possíveis do conceito em Aristóteles.” (ALVAREZ, 2012, p. 34.)

sem procurar uma coerência com as demais normas do ordenamento jurídico, podendo, inclusive, decidir contra a lei posta (contra legem).” (DAVID, 2015, p. 10-34.) 
Sua obra aborda a temática da aequitas em pelo menos duas oportunidades, quais sejam, na Suma Teológica, na questão 96, artigo 6 (I-II) e na questão 120 (II-II), sendo nesta última de forma direta.

Na primeira das passagens (Q 96), Tomás de Aquino articula, no artigo 6, sobre a possibilidade de se agir sem observância à letra da lei, naquilo que Giorgio Agamben menciona como o "poder do príncipe de dispensar a lei”:

A teoria da necessidade não é aqui outra coisa que uma teoria da exceção (dispensatio) em virtude da qual um caso particular escapa à obrigação da observância à lei. A necessidade não é fonte de lei e tampouco suspende, em sentido próprio, a lei; ela se limita a subtrair um caso particular à aplicação literal da norma.” (AGAMBEN, 2004, p. 41.)

As três objeções que são apontadas pelo autor são as seguintes: (i) não é permitido ao súdito deixar de lado a letra da lei para salvar a intenção do legislador; (ii) apenas quem pode fazer as leis têm legitimidade para interpretá-las, razão pela qual se deveria agir de acordo com a letra da lei; (iii) sendo o legislador um sábio, ele sabe expressar o que pretende com o uso das palavras, portanto suas intenções devem ser aferidas pelas palavras que usou ao formular a regra. As objeções, como se vê, além de relevantes à época, guardam até os dias de hoje repercussão nas discussões jusfilosóficas.

À primeira das objeções, Tomás responde que aquele que em caso de necessidade age contra as palavras da lei não julga a própria lei, mas sim o caso particular no qual as palavras da lei não podem ser aplicadas. Em relação à segunda objeção, Tomás argumenta que a interpretação é sobre o caso, e não sobre a lei, quando se mostra patente a existência de dano que não era previsto pelo legislador; em contrapartida, se a existência de dano não for evidente, deve-se ater à letra da lei (ou consultar o superior). Quanto à terceira objeção, a resposta é no sentido de que ninguém é tão sábio que possa prever todos os casos particulares, tampouco expressar suficientemente com palavras tudo que deva conduzir ao fim almejado. Veja-se que o fundamento de Tomás de Aquino para refutar a terceira objeção é exatamente o mesmo utilizado nos dias atuais por relevantes jusfilósofos - como adiante será visto - muito embora não façam menção à obra de Tomás de Aquino.

Nesse sentido, na medida em que "os contratos, os testamentos e as próprias leis não devem ser entendidos segundo a letra, mas antes segundo o espírito subjacente a cada caso" 
(CORDEIRO, 2016, p. 593), Daly comenta que a doutrina de Tomás de Aquino fundamenta-se no princípio de agir “praeter verba legis”, isto é, para além das palavras da lei:

E Sto. Tomás cita o exemplo de uma cidade sitiada onde a autoridade faz a lei de não abrir os portões, para proteger os cidadãos contra os inimigos exteriores. Então ele considera o caso excepcional em que um grupo de cidadãos, importante para a guarda da cidade, encontra-se fora e se dirige para os portões, perseguido de longe pelo inimigo. Nesse caso, ele diz que é preciso abrir os portões, pois mantê-los fechados seria “damnosissimum civitati” - injuriosíssimo para o bem comum querido pelo legislador. (DALY, 2012)

Deste modo, a solução consignada por Tomás de Aquino indica que, com frequência, o cumprimento de uma norma é proveitoso para o bem comum na generalidade dos casos, ainda que um determinado caso particular seja nocivo; mas, considerando que o legislador não tem capacidade para prever todos os casos que podem suceder, formula a lei em consonância com a ordinariedade dos casos. Como consequência, deve-se negar cumprimento à letra da lei se esta gerar danos ao bem comum quando de sua aplicação a um caso particular (AQUINO, 1989, p. 753, q. 96, a.6).

A respeito, Barzotto comenta que “a 'intenção do bem comum' ou a 'fidelidade à comunidade’ é o que autoriza um juiz a estabelecer uma exceção à aplicação de uma lei.” (BARZOTTO, 2007, p. 219-260.) Nesse contexto, a equidade, nas palavras de Alvarez, “não é a justiça que a lei determina” (ALVAREZ, 2012, p. 36).

John Finnis explica a posição de Tomás de Aquino argumentando que, para o Santo, os princípios gerais da razão prática possuem a mesma verdade e correção para todos (apud omnes), mas as conclusões específicas da razão prática não (FINNIS, 2004, p. 163).

Finnis apresenta o clássico exemplo de Tomás de Aquino de que a obrigação de devolver as coisas depositadas possui um sentido universal; entretanto, há ocasiões nas quais o mandamento não deve ser observado, "por outras obrigações de justiça” (FINNIS, 2004, p. 164). Finnis apresenta, em obra diversa, três elementos que seriam componentes da "reflexão moral clássica” para superação de “obrigação moral de obediência” à lei, elencando epieikeia, desuso da regra e injustiça. (FINNIS, 2011, p. 372.)

É na questão 120, porém, que Tomás de Aquino se dedica diretamente à equidade (ainda que muitas vezes reutilizando os argumentos anteriormente expostos). A questão 120 é 
composta por dois artigos: o primeiro questiona se a epieikeia é uma virtude; o segundo, se a epieikeia é parte da justiça.

Tomás de Aquino argumenta que a epieikeia não significa o oposto da severidade, uma vez que, quando a lei é rigorosa, deve-se pautar por tal rigor. Todavia, pondera que cumprir a letra da lei quando não se deve é pecado (AQUINO, 1955, p. 609, q. 120, a.1). Aqui, novamente apresenta o argumento de que dizer que não se deve cumprir a lei quando sua aplicação provoque danos não é julgar a lei, mas sim o caso concreto (AQUINO, 1955, p. 609, q. 120 , a.1).

Ao apresentar a solução em referência ao segundo artigo, Tomás de Aquino sustenta que se tomar-se por justiça legal a que se ajusta à lei (seja sua letra, seja seu espírito), então a epieikeia é parte da justiça legal; entretanto, se a justiça legal é compreendida apenas pelo sentido da letra da lei, então a epieikeia não é parte da justiça legal, sendo superior a esta (AQUINO, 1955, p. 611, q. 120, a.2).

\section{Conclusão}

A breve análise realizada aponta no sentido de que o pensamento aristotélico, assim como o pensamento de Tomás de Aquino, vislumbravam na equidade uma forma de se corrigir a aplicação da lei no caso concreto. Isto porque, dada a natural e necessária generalidade da lei, nem sempre as peculiaridades dos casos concretos seriam subsumíveis à norma geral de modo adequado.

Em outras palavras, pode-se dizer que a preocupação da equidade, em tal contexto, é no sentido de evitar que a aplicação da norma geral conduza a um resultado iníquo, por ser não desejado pelo legislador quando da formulação de tal norma.

Assim, dada a possibilidade de uma errônea subsunção, poder-se-ia proceder a um juízo corretivo da lei, para que seu sentido primário fosse preservado, em detrimento do seu sentido literal, o qual não seria o mais adequado à circunstância fática concreta.

Deste modo, vislumbra-se no entendimento aristotélico sobre a equidade uma forma apta à correção da lei na sua aplicação concreta, embora o método empregado em tal contexto 
(no qual o intérprete deve agir como se legislador fosse) possa não ser o mais adequado à atualidade juspositivista.

\section{Referências}

AGAMBEN, Giorgio. Estado de exceção. São Paulo: Boitempo, 2004.

ALVAREZ, Alejandro Montiel. A epieikeia e o nómos: uma análise do conceito de epieikeia a partir de uma tradição aristotélica. Orientador Luis Fernando Barzotto. Porto Alegre: UFRGS, 2012.

AMARAL, José António Campelo de Sousa. Modelação normativa no Direito e mesomorfologia da decisão em Aristóteles. In Artigos LusoSofia. Universidade da Beira Interior: Covilhã, 2014.

AQUINO, Tomás. Suma de teología. Madrid: Biblioteca de Autores Cristianos, 1955.

AQUINO, Tomás. Suma de teología. Madrid: Biblioteca de Autores Cristianos, 1989.

ARISTÓTELES. Política. Tradução Antonio Campelo Amaral e Carlos Gomes. Lisboa: Vega, 1998.

ARISTÓTELES. Ética a Nicômaco. Tradução de Edson Bini. Bauru: EDIPRO, 2002.

ARISTÓTELES. Retórica. Tradução de Edson Bini. São Paulo: EDIPRO, 2013.

ATIENZA, Manuel; MANERO, Juan Ruiz. Ilícitos atípicos: sobre o abuso de direito, fraude à lei e desvio de poder. São Paulo: Marcial Pons, 2014.

BARZOTTO, Luis Fernando. Razão de lei: contribuição a uma teoria do princípio da legalidade. In Revista Direito GV. Vol. 3, n. 2, jul-dez. 2007, p. 219-260. 
BITTAR, Eduardo C. B. A teoria aristotélica da justiça. In Revista da Faculdade de Direito da USP. Volume 92, ano 1997.

BITTAR, Eduardo C. B. Curso de filosofia aristotélica: leitura e interpretação do pensamento aristotélico. Barueri: Manole, 2003.

BITTAR, Eduardo C. B. A justiça em Aristóteles. Rio de Janeiro: Forense, 2005.

CAMPELO, Olívia Brandão Melo. Justiça: prudência. São Paulo: PUCSP, 2010.

CARMIGNANI, Maria Cristina. A aequitas e a aplicação do direito em Roma. In Revista da Faculdade de Direito da USP. Volume 104, ano 2009.

CHROUST, Anton-Hermann. Aristotle’s conception of equity (epieikeia). In Notre Dame Law Review, v. 18, issue 2, article 3, 1942, p. 119-128.

CORDEIRO, António Menezes. Tratado de Direito Civil. Volume 1. Coimbra: Almedina, 2016.

DAL MASS, Adroaldo. A lei como fonte de justiça em Aristóteles. Orientador Draiton Gonzaga de Souza. Porto Alegre: PUCRS, 2000.

DALY, John S. Epiquéia (conferência). Traduzido por F. Coelho. São Paulo, mar. 2012. Disponível em http://wp.me/pw2MJ-1gK.

DAVID, Tiago Bitencourt. O que ainda nos resta da epieikeia de Aristóteles: estudo sobre os conceitos e usos clássicos e contemporâneos de equidade. In Revista Jurídica, número 454, ago. 2015, p. 10-34.

FINNIS, John. Aquinas: moral, political, and legal theory. Oxford: Oxford University Press, 2004. 
FINNIS, John. Philosophy of law. Oxford: Oxford University Press, 2011.

GADAMER, Hans-Georg. Verdade e método I. Tradução Flávio Meurer. Petrópolis: Vozes, 2014.

GOYTISOLO, Juan B. Vallet. Metodologia de las leyes. Madrid: Editoriales de Derecho Reunidas, 1991.

GRAU, Eros Roberto. O direito posto e o direito pressuposto. São Paulo: Malheiros, 2008.

HOBUSS, João. Epieikeia e particularismo na ética de Aristóteles. In Revista ethic@. Florianópolis, v.9, n. 2, p. 163-174, dez. 2010.

HÖFFE, Otfried. Aristóteles. Tradução Roberto H. Pich. Porto Alegre: Artmed, 2008.

HÖFFE, Otfried. Justiça Política. Tradução Ernildo Stein. São Paulo: Martins Fontes, 2006. MacDONALD, Paulo Baptista Caruso. Lei, justiça e razão prática em Aristóteles. Orientador Alfredo Carlos Storck. Porto Alegre: UFRGS, 2010.

MICHON, Cyrille. L'epieikeia aristotélicienne comme correctif de la loi. In Annuaire de l’Institut Michel Villey. Volume 2, 2010, p. 33-48.

MORRALL, John. Aristóteles. Brasília: UnB, 2000.

PERELMAN, Chaïm. Ética e Direito. São Paulo: Martins Fontes, 1996.

PLATÃO. A República. Tradução de Maria Helena da Rocha Pereira. Lisboa: Fundação Calouste Gulbenkian, 2014.

PORTALIS, Jean-Étienne-Marie. Discours préliminaire du premier projet de Code civil. Bordeaux : Éditions Confluences, 2004. 
SHINER, Roger A. Aristotle’s theory of equity. In Loyola of Los Angeles Law Review, vol. 27, 1994, p. 1245-1264.

SILVA, Matheus Teixeira. A excepcionabilidade normativa no processo decisório. Porto Alegre: Núria Fabris, 2015.

TEIXEIRA, Anderson Vichinkeski. A equidade na Filosofia do Direito: apontamentos sobre sua origem aristotélica. In Revista Espaço Acadêmico, n. 128, jan/2012, p. 88-92.

ZIPPELIUS, Reinhold. Filosofia do direito. São Paulo: Saraiva, 2012. 